\title{
Towards a mental representation of vowel height in SSBE speakers
}

\author{
Kevin Mendousse \\ School of European Languages \& Literatures, University of Auckland, New Zealand \\ https://doi.org/10.36505/ExLing-2011/04/0024/000193
}

\begin{abstract}
Debate in phonetics and phonology has focused on the cognitive foundation of distinctive feature theory, as well as on the definition of features themselves. Although the motor-acoustic feature of vowel height has been the object of close scrutiny, research on the vertical representation of vowels in the phonology of English remains inconclusive. By drawing on Sapir's work on phonetic symbolism, this paper investigates the understanding that SSBE speakers have of their own vowel space. It argues that their implicit knowledge of vowel height differences is best accounted for in terms of a threetiered vertical axis.
\end{abstract}

Key words: phonetic symbolism, phonological perception, vowel height

\section{Phonological framework}

Beneath the profound differences separating Jakobson, Fant and Halle (1952) and Chomsky and Halle (1968) lies a shared belief that, logically, distinctive features must be binary. In the case of RP English, the former make no difference between long monophthongs and diphthongs, both types of vowels being assigned a geminate nuclear structure consisting of a) an initial stressed vowel and b) a final unstressed non-syllabic off-glide. Consequently, the phonologically relevant feature in both phonetic oppositions phonetic oppositions [I] [i:] and [v] [u:] is said to be one of nuclear structure $\left(/ \mathrm{uu}^{\prime} / \sim / \mathrm{u}^{\prime} /, / \mathrm{i}^{\prime} / \mathrm{I}^{\prime} /\right)$, not height. As argued by Mendousse (2007), and in keeping with Jakobson's (1949) pledge to Ockham's Razor, the feature [stressed/unstressed] allowed Jakobson, Fant and Halle (1952) to cut back on 1 of 3 vowel primes and downsize Jones' (1918) set of 20 vowel phonemes to 12.

Chomsky and Halle (1968) in turn rejected Jakobson's creed of parsimony and unwavering belief in the primacy of acoustic cues, which failed to account for the underlying symmetry between palatalisation and front vowels, and velarisation and back vowels. Instead, they provided an articulatory-based variant system where their motor features [ \pm high/low], $[ \pm$ front/back] and $[ \pm$ round/ nonround] only partly overlapped with acoustic features [ \pm diffuse/compact], [ \pm grave/acute] and $[ \pm$ flat/natural $]$. They also postulated the feature $[ \pm$ tense/ lax] by virtue of which only underlying tense vowels are made to undergo their advocated Vowel Shift Rule and Diphthongization Rule: surface and

ExLing 2011: Proceedings of 4th Tutorial and Research Workshop on Experimental Linguistics, 25-27 May, Paris, France 
would thus derive fromunderlying /i/ and $/ \bar{\varepsilon} /$, in contrast to Jakobson, Fant and Halle (1952) who assigned equal phonological height to both vowels via the phonemic opposition /'i/ /'ii /; conversely, where the latter posited a phonological height difference in $[\varepsilon] \sim[i:]$ via the phonemic opposition $/{ }^{\prime} \varepsilon / \sim /$ ' $i$ i $/$, Chomsky and Halle (1968) placed them on a vertical par via underlying $/ \varepsilon / \sim / \bar{\varepsilon} /$.

Such differences notwithstanding, both paradigms endorsed a given set of features whose scalar values on the phonetic continuum are filtered down, phonologically, to raw binary oppositions. But the binary doctrine itself is not without its dissenters. In the wake of Ladefoged (1971), who included the feature $[ \pm$ mid] in order to account for a fourth degree of

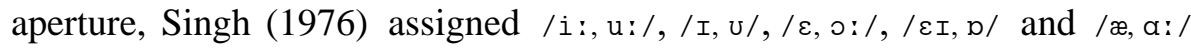
the multi-valued tongue height features [5 high], [4 high], [3 high], [2 high] and [1 high]. Actual tongue height measurements, however, have often been found at variance with their conventional representation on the vowel quadrilateral (Durand 1990). While acknowledging the relevance of tongue height in the study of vowel production, Ladefoged (1971) questioned their value in phonology and recommended primacy be given to the auditory-acoustic correlates of distinctive features given that formant charts yield a more accurate picture of reality than articulatory descriptions. Since then, advocates of the motor theory of speech perception have argued for a more abstract level of articulation, where motor gestures used to decode speech to key articulators correspond to speakers' intentions (Liberman and Mattingly 1985). As noted by Durand (1990: 69), critics have dubbed this readjustment as "the retreat up the vocal tract", but proponents of auditory-acoustic theories in turn are faced with the difficulty that no single cue corresponds to one phonetic category and that acoustic records mesh only indirectly with auditory percepts.

\section{Experimental framework}

Heeding the advice of Trubetzkoy (1931), for whom the "linguistic unconscious" should serve as a phonological compass, we undertook to integrate Sapir's (1929) pioneering work on phonetic symbolism within the paradigm of distinctive feature theory. Results of his study have firmly established the unconsciously synaesthetic correlation between speakers' perception of vowel-size differences and actual motor-acoustic (dis)similarities, which Fónagy (1980) later developed into a model of metaphoric ideation where phonetic metaphors are said to be the symbolic projection of speakers' intersensory image of sounds. In the simplest of cases, the actual size or volume of the stimulus is mimetically connected to the articulatory gesture itself, such as the degree of aperture or volume of the resonance chambers. 
Towards a mental representation of vowel height in SSBE speakers 101

The scope and cross-cultural consistency of the metalanguage used in phonetics also points to more complex perceptual patterns arising from associative learning mechanisms that correlate size with pitch (Peterfalvi 1970). By allowing for both symbolic responses a) "larger/smaller" vowel $\leftrightarrow$ "wider/narrower" $\leftrightarrow[+$ low $] /[+$ high $]$ and b) "larger/smaller" vowel $\leftrightarrow$ "heavier/lighter" $\leftrightarrow[+$ compact]/[+diffuse], phonetic metaphors circumvent the debate on the motor-acoustic content of distinctive features. Furthermore, Taylor and Taylor's (1962) empirical study demonstrates that speakers are sound-symbolically insensitive to allophonic variations, in which case their vowel-size rankings may be construed as the symbolic projection of their implicit feature knowledge of vowel height differences. In order to assess their mental representation of such differences, participants were thus handed out a vowel-size survey questionnaire and asked, in a forced-choice selection task, to choose from each of 30 nonword minimal pairs the term most likely to mean "smaller" or "larger".

\section{Results}

114 completed questionnaires were collected, yielding the following statistically significant front and back vowel-size rankings: $\{[i:, I]<[\varepsilon$, $\varepsilon I]<[æ$, aI $]\},\{[u:, v]<[o v]<[o I, o:]\}$. These findings strongly support the three-tiered definition of vowel height advocated in binary feature theories, and hence call into question the need, in the name of phonetic realism, for all vowels to be phonologically distinct with respect to height. Back vowel-size rankings, however, remain at odds with Lilly and Viel's (1998) equal midvowel height plotting of $\{/ \mathrm{O}:$, oI $/\}$.

Moreover, the non-rejection of the null (random) hypothesis $\mathrm{H} 0$ in $\{[I] \sim[i:],[U] \sim[u:]\}$ and simultaneous rejection in $\{[I] \sim[a I],[\varepsilon] \sim[i:]$, $[æ] \sim[\varepsilon 工],[0] \sim[\circ\}],[\mho] \sim[0:]\}$ go against the alleged psychological reality of Chomsky and Halle's (1968) Vowel Shift Rule: deriving the former from underlying $\{/ \mathrm{i} / \sim / \bar{\varepsilon} /, / \mathrm{u} / \sim / \overline{\mathrm{o}} /\}$ incorrectly predicts $\mathrm{H} 0$ to be untrue, while deriving the latter from underlying $\{/ \mathrm{i} / \sim / \overline{\mathrm{l}} /, / \varepsilon / \sim / \bar{\varepsilon} /, / \Re / \sim / \overline{\mathfrak{x}} /, / 0 / \sim / \bar{\zeta} /$, $/ \mathrm{u} / \sim / \overline{\mathrm{u}} /\}$ incorrectly predicts the opposite.

The above results invalidate motor-acoustic height as a phonologically relevant feature in $\{[\mathrm{I}] \sim[\mathrm{i}:],[\cup] \sim[u:]\}$. Halle and Stevens' (1969) [ \pm ATR/RTR] feature opposition, which they appended to Chomsky and Halle's (1968) inventory as an alternative to vowel tenseness in order to account phonologically for a fourth degree of aperture, is an equally unlikely candidate: participants did not respond symbolically to the ATR-associated widening of the pharyngeal cavity in $[i:]$ and $[u:]$ by rating $\{[I],[v]\}$ and $\{[i:],[u:]\}$ vowels as being respectively "smaller" and "larger". Phonemically, such vowel pairs have been alternatively defined as /V/ /V:/ (Jones 1918) and /'V/ /' $V_{1} V_{1} /$ (Jakobson, Fant and Halle 1952). The 
psychological (in)adequacy of each the aforementioned phonological definitions remains a matter for further empirical study.

\section{References}

Chomsky, N., Halle, M. 1968. The Sound Pattern of English. New York: Harper \& Row.

Durand, J. 1990. Generative and Non-Linear Phonology. London: Longman.

Fónagy, I. 1980. La métaphore en phonétique. Studia Phonetica 16, xi-220.

Halle, M., Stevens, K.N. 1969. On the feature "advanced tongue root". MIT Quarterly Progress Report 94, 209-215.

Jakobson, R. 1949. On the identification of phonemic entities. In Jakobson, R. 1962, Selected Writings I, 418-425. The Hague, Mouton.

Jakobson, R., Fant, G., Halle, M. 1952. Preliminaries to Speech Analysis: The Distinctive Features and their Correlates. In Jakobson, R. 1987, Selected Writings VIII, 585-654. Berlin, Mouton.

Jones, D. 1918. An Outline of English Phonetics. Cambridge: Heffer \& Sons.

Ladefoged, P. 1971. Preliminaries to Linguistic Phonetics. Chicago: University of Chicago Press.

Liberman, A.M., Mattingly, I.G. 1985. The motor theory of speech perception revised. Cognition 21, 1-36.

Lilly, R., Viel, M. 1998. Initiation Raisonnée à la Phonétique de l'Anglais. Paris: Hachette.

Mendousse, K. 2007. Le dilemme de Roman Jakobson face à l'opposition de tension/laxité vocalique. Histoire Epistémologie Langage 29.1, 29-68.

Peterfalvi, J.-M. 1970. Recherches Expérimentales sur le Symbolisme Phonétique. Paris: CNRS.

Sapir, E. 1929. A study in phonetic symbolism. In Mandelbaumm, D. G. (ed.) 1949, Selected Writings of Edward Sapir in Language, Culture and Personality, 61-72. Berkeley, University of California Press.

Singh, S. 1976. Distinctive Features: Theory and Validation. Baltimore: University Park Press.

Taylor, I.K., Taylor, M.M. 1962. Phonetic symbolism in four unrelated languages. Canadian Journal of Psychology 16, 344-356.

Trubetzkoy, N.S. 1931. Die phonologischen Systeme. Travaux du Cercle Linguistique de Prague 4, 96-116. 